\title{
CYBERSTALKING ... NO MEANS NO: AN EXPLORATORY STUDY OF UNIVERSITY STUDENTS
}

\author{
Karen Paullet, Robert Morris University, paullet@rmu.edu \\ Adnan Chawdhry, California University of PA, chawdhry_A@calu.edu
}

\begin{abstract}
Increased use of technology and the internet have allowed for better means of communications while removing the geographic boundaries that once existed. However, the added benefit can soon be diminished when technology is in the hands of a stalker. Cyberstalking is relatively new but has posed life threatening safety concerns for individuals around the world. This exploratory study of 121 students examines incidents of cyberstalking by evaluating the style and length of communications between a stalker and victim along with the perceived level of fear related to the incident. The study illustrates that it is essential to report these incidents immediately and to the right authority before it is too late. Awareness of cyberstalking and guidelines to mitigate the risk are essential steps to keep yourself safe from incidents, no matter how harmless they may seem.
\end{abstract}

Keywords: Cyberstalking, Online Harassment, Stalking, Electronic Communication

\section{INTRODUCTION}

One of the earliest documented cases is the stalking of President Andrew Jackson in 1835. The President was stalked by Richard Lawrence who ultimately tried to assassinate him. Lawrence believed it was the President's fault for his financial problems. According to the Department of Justice (2020), stalking means engaging in a course of conduct directed at a specific person that would cause a reasonable person to fear for his or her safety often causing substantial emotional distress. Stalking is a repetitive pattern of unwanted, harassing or threatening behavior committed by one person against another (Olgivie, 2000).

With the use of the Internet and the wide-spread use of cellular technology, what was once known as stalking has turned into cyberstalking. Cyberstalking is a relatively new crime that has been examined and reported since the late 1990's (Rota, 2009). Using technology to stalk a victim can include, but is not limited to, the Internet, e-mail, text messaging, global positional systems (GPS), mobile devices, mobile apps and social network sites to name a few. One of the differences between cyberstalking and offline stalking is that cyberstalkers have no geographic boundaries. The Internet makes it possible for a person to be stalked virtually anywhere in the world. Cyberstalking "entails the same general characteristics as traditional stalking, but in being transposed into the virtual environment as it is fundamentally transformed (Olgivie, 2000).

People should be able to feel safe when they use technology without being stalked or harassed. The increased use of mobile technology has led to an increase in the number of cyberstalking cases. The purpose of this research study is to explore online harassing/cyberstalking experiences of students at two Mid-Atlantic Universities by understanding its impacts and perceived fear for a cyberstalking incident.

\section{LITERATURE REVIEW}

Duggan conducted a Pew Research study on online harassment of 4,248 U.S. adults in 2017 (Duggan, 2017). The study revealed that $14 \%$ say there were harassed online due to their political views, while $9 \%$ have been harassed due to their physical appearance, $8 \%$ race, $8 \%$ gender, $5 \%$ religion and 3\% sexual orientation. Americans are aware of online harassment in which $62 \%$ believe that it is a major problem. Despite this broad concern over online harassment, Americans are more divided over how to balance protecting free expression online and preventing behavior that crosses into abuse. When asked how they would prioritize these competing interests, $45 \%$ of Americans say it is more 


\section{Issues in Information Systems}

Volume 21, Issue 1, pp. 125-130, 2020

important to let people speak their minds freely online; a slightly larger share (53\%) feels that it is more important for people to feel welcome and safe online.

The Center for Innovative Public Health Research (2016) conducted a study on online harassment, digital abuse and cyberstalking in American. Lenhart and Zickhur (2016) surveyed 3,002 of U.S. teens and adults who witnessed or experienced online harassment and abuse. The study revealed that $47 \%$ of Internet uses have experience online harassment or abuse. Of those surveyed, $36 \%$ have experienced direct harassment. Men and women are equally likely to fact harassment, but women experience online abuse with more serious violations. Additionally, $72 \%$ of Internet users have witnessed at one harassing behavior online and 4 in ten victims of online harassment have changed their contact information.

Tjaden and Thoennes (1998) conducted a national telephone survey of 8,000 women and 8,000 men. The study revealed that among individuals between the ages of 18 to $28,52 \%$ were most at risk of becoming a victim of cyberstalking. Victims from the study revealed that $78 \%$ of the victims were women and $22 \%$ were men. Victims reported in $78 \%$ of the cases that they were stalked by someone that they did not know.

Bocji (2003), conducted a web-based survey on the prevalence and impact of cyberstalking. A total of 169 students completed the survey where $22 \%$ were genuine cyberstalking cases in which $62 \%$ were female. The study showed that $42 \%$ did not know the identity of their stalker, $9 \%$ responded they were stalked by an ex-partner, $16 \%$ by a friend, $2 \%$ from someone at work and $32 \%$ by other means. According to Bocji (2003), cyberstalking represents a form of behavior where technology is used to harass one or more individuals.

Finn (2014) conducted an exploratory study of online harassment at a University campus. The study surveyed 339 students at the University of New Hampshire in which $15 \%$ of students reported receiving repeated threatening or harassing email or instant messages. The study revealed that $7 \%$ of students reported the harassment to an authority. A study conducted by Hensler-McGinnis (2008) investigated the impact of cyberstalking victimization of 452 undergraduate and graduate University students. The study showed that $46 \%$ of student met the legal criteria for being a victim of cyberstalking. The study identified victims as having experienced cyberstalking or cyberstalking behaviors. More than half, $54 \%$ of respondents indicated they did not feel threated or afraid of their cyberstalker.

Knowing the types of Internet technologies used by a cyberstalker can help with law enforcement training and setting the budget. "Understanding how offenders use the Internet to stalk victims in cyberspace can provide law enforcement officers with solutions when they encounter impediments investigating these types of cases" (D'Ovidio, 2003). A 1995 study, which involved the New York City Police Department's (NYPD) Computer Investigation and Technology Unit (CITU), used police records to study the extent of cyberstalking. The data in the study was gathered from reports filed by the victim along with police reports showing the progression of investigation used in a reported case. The data was collected form closed cases in which the criminal used the Internet to stalk or harass a victim (D'Ovidio \& Doyle, 2009).

During the NYPD study, 42.8\% of the cases investigated by the CITU involved online harassment. There were 192 closed cases examined for the study. Of the 192 cases, $40 \%$ were closed with an arrest while $11 \%$ of the cases did not show enough evidence that a crime was committed. The remaining cases for closed for reasons such as uncooperative victim, transfer of the case or the CITU could not find the suspect. Email was used to stalk the victims in $72 \%$ of the cases examined (D’Ovidio \& Doyle, 2009).

\section{RESEARCH METHODOLOGY}

The study surveyed students attending two small mid-Atlantic Universities from March to April 2018. The population chosen for this study includes undergraduate and graduate students enrolled in on-campus or online programs. The sample of 121 students represented a subset of the student population who were 18 years of age or older. The study collected participant responses using an online tool called Survey Monkey. The results were imported into IBM SPSS for further organization and statistical analysis. In part of the analysis, the researchers utilized Chi-square correlation to identify statistical significance with a .05 or less margin of error and a $95 \%$ confidence interval. The study addressed the following two research questions: 
RQ1 - What impacts do the style and length communication have on actions taken by victims?

RQ2 - How does the level of fear perceived by the victim impact actions they take?

Prior to administering the survey, the researchers piloted the study with 10 post-graduate students. Their feedback included modifying question wording and updates to the responses listed for each question. The survey consisted of 19 questions, including 1 open-ended question to understand what participants did to end cyberstalking. Additionally, the questions addressed how individuals used the internet, information regarding their cyberstalking, incidents that occurred online and how the participants addressed or notified others when they were involved in an incident.

\section{RESULTS}

The researchers found it important to examine demographic information related to the participants. Of the participants, $62.81 \%$ were female while $37.19 \%$ were male. Additionally, $81.82 \%$ of the participants were between $18-25$ years old with the percentages trailing off as the age categories increased. Students were studied at various levels of education. The distribution consisted of $82.65 \%$ of the students being enrolled in undergraduate programs where the largest segment of students at the Junior and Sophomore levels. Lastly, $17.35 \%$ of the participants were enrolled in the graduate and post-graduate programs. One of the survey questions asked if participants have been or currently are a victim of cyberstalking based upon the definition provided at the beginning of the survey. Of the participants, $31.4 \%$ stated they had been a victim of cyberstalking.

Only participants who responded they had a cyberstalking incident were asked to continue with the survey. The next question asked those participants how long they the cyberstalking encounter lasted. Additionally, participants were asked if they reported their incident to an authority. Table 1 below summarizes these questions to understand if the incident length had any correlation to reporting the incident. Based upon the results below, the study had concluded that the vast majority of incidents were reported within the first month or great than six months. However, the study did not find a statistical significance between reporting the incident and the length of the incident. As the communication style moves from less harmful (friendly and sexual) to more harmful (threatening, hateful, and intimidating), it is evident that the more harmful ones had a higher percentage of participants who reported the issue. This is a clear indication that as people perceived the threat to be greater, they took action as a result of it. You can find the full details of reporting the incident compared to the style of communication in Table 2 below.

Table 1. Reporting an Incident vs Length of Incident

\begin{tabular}{|lcccccc|}
\hline $\begin{array}{l}\text { Report the } \\
\text { Incident }\end{array}$ & $\begin{array}{c}\text { Less than } \\
\text { one month }\end{array}$ & $\mathbf{1 - 3}$ months & 4-6 months & $\mathbf{7 - 1 2}$ months & $\begin{array}{c}\text { More than } 1 \\
\text { year }\end{array}$ & Ongoing \\
\hline No & $18.75 \%$ & $6.25 \%$ & $0.00 \%$ & $6.25 \%$ & $6.25 \%$ & $12.50 \%$ \\
\hline Yes & $12.50 \%$ & $6.25 \%$ & $6.25 \%$ & $12.50 \%$ & $6.25 \%$ & $6.25 \%$ \\
\hline
\end{tabular}

Table 2. Reporting an Incident Vs Style of Communication

\begin{tabular}{|lccccc|}
$\begin{array}{l}\text { Report the } \\
\text { Incident }\end{array}$ & Friendly & Sexual & Threatening & Hateful & Intimidating \\
\hline No & $37.50 \%$ & $31.25 \%$ & $18.75 \%$ & $18.75 \%$ & $25.00 \%$ \\
\hline Yes & $12.50 \%$ & $31.25 \%$ & $37.50 \%$ & $25.00 \%$ & $31.25 \%$ \\
\hline
\end{tabular}

The second focus of this study was to understand the level of fear perceived by the participants who encountered a cyberstalking incident. Half of the participants reported a Moderate Level of fear followed by $37.5 \%$ who reported a High Level of fear and lastly $12.5 \%$ who reported a Low Level of fear. Using the perceived level of fear, the study compared it to the participants reporting the incident. Interesting enough, the higher level of fear, the more likely the incident was reported. As expected, the largest percentage to report the incident was when the perceived fear was High Level. The chi-square produced a value of 0.00 illustrating there was a correlation between the level of fear and if the participant reported it. The breakdown of this analysis is available in Table 3 below. 


\section{Issues in Information Systems}

Volume 21, Issue 1, pp. 125-130, 2020

Table 3. Level of fear versus Reporting the Incident

\begin{tabular}{|lcc|} 
& \multicolumn{2}{c|}{ Reported Incident } \\
\hline Level of Fear & Yes & No \\
\hline High Level & $31.25 \%$ & $6.25 \%$ \\
\hline Moderate Level & $18.75 \%$ & $31.25 \%$ \\
\hline Low Level & $0.00 \%$ & $12.50 \%$ \\
\hline
\end{tabular}

After understanding the participant had reported the incident, it was assess which reporting authority was contacted. The participants were provided with options such as the Campus Advisor, Cell Phone Provider, Law Enforcement, and Other. These variables produced a chi-square value of .17 which illustrated the variables were not statistically significant. However, one conclusion we could draw is that as the perceived fear was increased, the participants turned more towards law enforcement. Additionally, it was important to understand if the participants received the help they needed from these authorities. Twenty-five percent of the participants reported a High Level of fear and received help. However, $12.5 \%$ of those that reported a High Level of fear did not receive help. The Moderate Level did not receive help even though they reported the incident. Lastly, $18.75 \%$ of the participants reported a Low Level of fear and received help while $12.5 \%$ did not receive help. Unfortunately, these two variables were not seen to be statistically significant. The results of these questions are summarized in Table 4 and 5 below.

Table 4. Level of Fear versus Reporting Authority

\begin{tabular}{|lrrrr|}
\hline & Campus Advisor & Cell Provider & Law Enforcement & \multicolumn{1}{c|}{ Other } \\
\hline High Level & $6.25 \%$ & $6.25 \%$ & $18.75 \%$ & $6.25 \%$ \\
\hline Moderate Level & $0.00 \%$ & $0.00 \%$ & $12.50 \%$ & $31.25 \%$ \\
\hline Low Level & $0.00 \%$ & $0.00 \%$ & $0.00 \%$ & $12.50 \%$ \\
\hline
\end{tabular}

Table 5. Level of Fear versus Received Help

\begin{tabular}{|lrr|}
\hline & Yes & \multicolumn{2}{c|}{ No } \\
\hline High Level & $25.00 \%$ & $12.50 \%$ \\
\hline Moderate Level & $0.00 \%$ & $31.25 \%$ \\
\hline Low Level & $18.75 \%$ & $12.50 \%$ \\
\hline
\end{tabular}

Lastly, the survey concluded by asking the participants what other alternatives they used to help end the cyberstalking incidents. Below are their responses / methods used:

- Blocking the cyberstalker's phone number

- Protection from Abuse order

- Disabled location tracking to ensure safety.

- Social Media
- Blocking the cyberstalker
- Tighten privacy settings
- Decline friend requests that you do not recognize.
$\circ$ Do not provide home address or phone number

\section{DISCUSSION}

Being the victim of cyberstalking is very tragic and can lead to safety concerns. In some cases, stalking can be harmless but disruptive in nature. In order to understand the impacts of cyberstalking, the research analyzed the length of time the incidents occurred and how they are correlated to the style of communication. While the participants' responses did not yield very clear results that were statistically significant, we were able to develop patterns and trends from the data. First, it was important to note that fewer people reported the incidents while they occurred between 1 and 7 months. An assumption from this data is that the incidents became more threatening to the victim as more time 


\section{Issues in Information Systems}

Volume 21, Issue 1, pp. 125-130, 2020

passed. Also, to others, the incident was a threat immediately as it occurred. There is a direct relationship between the reporting and length of the incident after the initial month of contact. Second, it was equally important to see if the style of communication was a factor in reporting the issue. The results illustrated that the least harmful category of "friendly" had the lowest response of reporting the incidents. Assuming you consider the other categories of sexual, hateful, intimidating, and threatening to be an increased perception of harm, you can see that the incidents were reported more frequently. While we don't specifically rank these four categories, it was clear that the incidents are more harmful given the increased number of participants who reported the issue.

Another component to consider in cyberstalking is the perception of fear and how it impacts the actions taken by the victim. Half of the sample reported a Moderate Level of fear with High Level being next and followed by Low Level. One important note is that as the perceived level of fear increased, more of the cyberstalking instances were reported to an authority figure. This aligns with the expectation that as you fear more, you will take an appropriate action. In reporting the incidents, it was not as common for people to turn to a campus advisor or cell phone provider. In contrast, it was more common for the victim to turn to law enforcement and other sources in its place. One can interpret this as the victims turned to authorities who can take more action versus providing guidance on the incidents. The participants were then asked if they received help when reporting the incident. Given the large response rate of Moderate Level, it was unfortunate to see that the victims found they didn't receive any help for their reported incident. In both high and low levels of fear, some participants did receive help. Sadly, it was alarming to see that participants who perceived a High Level of fear did not receive help for the incident they reported.

Cyberstalking seems to be increasing and, in many cases, it is difficult to know what to do. Below are recommended approaches to prevent cyberstalking:

- When online, only type things you would actually say to someone face-to-face. Think about how what you say might be interpreted without eye contact, body language or voice.

- Think about what you are writing before you post or send a message.

- Save all communications from the stalker

- Avoid posting personal data on social media

- Be mindful of your passwords,

- Be wary of emails, texts, phone calls that ask for personal information

- Conduct an Internet search of your name regularly

- Report cases of cyberstalking to authorities.

\section{CONCLUSION}

Cyberstalking is becoming a greater threat and concern each year which threatens the safety and security of individuals as it has no geographic bounds. Being the victim of such an attack can leave you feeling very scared, unsure of what to do or who to talk to and left paralyzed emotionally. It is very important to assess your situation and understand what to if you are the victim of a cyberstalking incident. And it is equally important to know that you should always speak up early and error on the side of caution before it gets to an unsafe point. However, it is very important to realize there are steps we can take to help reduce the possibility of these Awareness and guidance are pivotal in preventing cyberstalking, but most importantly remember "no means no" and you should always report cyberstalking incidents immediately.

\section{REFERENCES}

Bocji, P. (2003). Victims of cyberstalking: An exploratory study of harassment perpetrated via The Internet. First Monday, Vol. 8, No. 10

DOJ. (2020). Stalking. Retrieved from https://www.justice.gov/ovw/stalking

Duggan, M. (2017). Online harassment 2017. Pew Research Center Internet and Technology. Retrieved from https://www.pewresearch.org/internet/2017/07/11/online-harassment-2017/

Finn, J. (2204). A survey of online harassment at a university campus. Journal of Interpersonal Violence. Sage Publications 


\section{Issues in Information Systems}

Volume 21, Issue 1, pp. 125-130, 2020

Hensler-McGinnis, N.F. (2008). Cyberstalking victimization: Impact and coping responses in a national university sample. Doctoral dissertation, University of Maryland, College Park, Maryland

Lenhart, A., \& Zickuhr (2016). Online harassment, digital abuse, and cyberstalking in America. Center for Innovative Public Health Research. Society Research Institute. Report 11.21.16

Ogilvie, E. (2000). The internet and cyberstalking. Stalking: Criminal Justice Conference, Sydney, Australian Institute of Criminology

Rota, D. (2009). Cyberstalking: An exploratory study of students at a mid-atlantic university. Issues in Information Systems, Vol X, No. 2, 2009

Tjaden, P., \& Theonnes, N. (1998). Stalking in America: Findings from the national violence against women survey. Washington DC: US Department of Justice, Centers for Disease Control and Prevention. 